\title{
Comparison of Contract General Conditions between United States and China
}

\author{
Ka Wah (Calvin) Chui, P.E. ; and Yong Bai, Ph.D., P.E., M.ASCE ${ }^{2}$
}

\begin{abstract}
In light of the fact that construction projects are expensive, complex, and time-consuming undertakings, a well-written contract that specifies each participant's duties and obligations is required. Furthermore, a well-written contract with regard to business practice differences between the United States and China is unquestionably needed by American owners, design firms, and construction companies conducting business in China. In response to this industry need, general conditions of construction contracts commonly used in the United States (AIA-A201) and China (GF-1999-0201) have been analyzed and compared. The findings of this research reveal that the content of subclauses in AIA-A201 and GF-1999-0201 is different in several ways. These differences may have been caused by cultural, historical, geographical, political, and language variations that exist between the American and Chinese construction markets. Understanding these differences could help U.S. companies stay competitive and profitable in China.
\end{abstract}

DOI: 10.1061/(ASCE)AE.1943-5568.0000020

CE Database subject headings: Construction industry; Contracts; China; United States; Comparative studies.

Author keywords: Construction; Contract; General conditions; China.

\section{Introduction}

For many years, construction has been the largest production industry in the American economy (Clough et al. 2005; Hinze 2001). According to The Associated General Contract of America (2010), for every billion dollars of new construction about 15,000 jobs are created in construction, supplies, and service industries. Of the 15,000 jobs created almost 9,700 are in the construction industry itself. In addition, due to globalization of the construction market, the U.S. construction industry has extended its reach to different corners around the world in the form of contracted projects and labor cooperation with other countries.

Because of the growing economy in China, many U.S. manufacturers (owners), architectural and engineering firms, and construction companies have invested a great deal of money to build facilities in China in order to take advantage of the low labor costs. According to National Bureau of Statistics of China (2009), the direct construction spending in China has grown from U.S. $\$ 127$ billion in 2004 to U.S. \$250 billion in 2008. In addition, according to the Chinese Ministry of Transportation, China will spend U.S. $\$ 240$ billion in the next 30 years to build $85,000 \mathrm{~km}$ of highways. These investment activities have brought many U.S. design firms and construction companies into the Chinese market. Some of these companies have stayed in China to compete for

${ }^{1}$ Ph.D. Candidate, Dept. of Civil, Environmental, and Architectural Engineering, Univ. of Kansas, 1530 W. 15th St., 2150 Learned Hall, Lawrence, KS 66045. E-mail: kawah.chui@gmail.com

${ }^{2}$ Associate Professor, Dept. of Civil, Environmental, and Architectural Engineering, Univ. of Kansas, 1530 W. 15th St., 2150 Learned Hall, Lawrence, KS 66045 (corresponding author). E-mail: ybai@ku.edu

Note. This manuscript was submitted on December 24, 2008; approved on March 10, 2010; published online on March 16, 2010. Discussion period open until May 1, 2011; separate discussions must be submitted for individual papers. This paper is part of the Journal of Architectural Engineering, Vol. 16, No. 4, December 1, 2010. (CASCE, ISSN 1076-0431/2010/4-119-125/\$25.00. new opportunities in the local market after they have finished their initial projects.

In light of the fact that construction projects are expensive, complex, and time-consuming undertakings, a structure must be designed in accordance with applicable codes and standards, culminating in working drawings and specifications that describe the work in sufficient detail for its accomplishment in the field (Clough et al. 2005). Thus, a well-written construction contract that specifies each participant's duties and obligations is required.

A construction contract contains many nontechnical provisions such as general conditions, supplementary conditions, and provisions of the agreement that pertain to the conduct of the work (Clough et al. 2005); these clauses provide a clear idea of each party's rights and obligations. An important, if not the most important, part of the construction contract is the general-conditions document (Fisk 2002). The general-conditions document, often referred to as the boilerplate, augments the construction contract, outlines the ground rules under which the project will be constructed, and spells out clearly and completely the rights, authority, and obligations of all the parties (Bockrath 2000; Hinze 2001). These rules are often lengthy and deal with subjects such as scope of contract documents and resolution of conflict between them, payments and completion, protection from and risk of loss to persons and property, disputes, etc. (Sweet 1999). Bubshait and Almohawis (1994) further identified that the importance of these documents stems from their role in defining the relationships, rights, and responsibilities of the contracting parties in all the projects within an agency or a country. Furthermore, the generalconditions document spells out the general project rules and relevant commercial terms.

Owing to the important role of the general conditions, coupled with their intended applicability in all the projects within an organization or even a country, general conditions are usually expressed in a standardized prepared printed contract form developed and published by different professional associations and bodies [e.g., American Institute of Architects (AIA) and ASCE] and are in wide use throughout the construction industry. 
The wide usage reflects the recognition of the advantages of using standardized general conditions. One of the major advantages identified by Bubshait and Almohawis (1994) is the familiarity of the contracting parties with the relevant provisions of the contract. Such familiarity will reduce the time and effort needed to prepare and review the contract documents and will contribute to reducing the bid-price contingencies. Another major advantage of using standard general conditions is that these general conditions have often been court tested so that the legal interpretation is known (Hinze 2001). In brief, standard general conditions lessen the possibility of misunderstanding, undue compensation, the likelihood of change orders, and the occurrence of claims or litigation arising out of contractual performance. In the United States, the owners, contractors, architects, and engineers can select standardized forms of general conditions of construction contract from a variety of sources. Some common ones are listed as follows:

1. General conditions developed by the AIA.

2. General conditions developed by the Associated General Contractor (AGC) and the ASCE.

3. General conditions developed by the U.S. government for public contracts (Federal Acquisition Regulations).

4. General conditions developed by the Engineers Joint Contract Documents Committee (ASCE, National Society of Professional Engineers, American Consulting Engineers Council, and Construction Specifications Institute).

The most common source of the general-conditions documents used in the United States for building construction is AIA-A201 (2007 Edition) which is published by the AIA. On the other hand, in China, Conditions of Contract for Works of Building Construction (GF-1999-0201) is the main source of the general-conditions documents. Despite the well-developed general conditions of construction contracts in the United States and China, respectively, there are a number of complex challenges due to culture differences that must be addressed when U.S. design firms and construction companies attempt to enter the Chinese market. Therefore, a well-written construction contract, specifically a general-conditions document, with particular regard to business practice differences between the United States and China is unquestionably needed by the U.S. owners, design firms, and construction companies that are conducting business in the Chinese market.

\section{Research Objective and Methodology}

In response to this industry need, the purpose of this study was to analyze and compare general conditions of construction contracts that are commonly used in the United States (AIA-A201) and China (GF-1999-0201). The objectives of the research were as follows:

1. To identify appropriate contents in the GF-1999-0201 document that could be adopted by U.S. firms which conduct business in China;

2. To provide guidelines for future development of general conditions of construction contract in the Chinese market; and

3. To offer means of decision making for American companies on implementation of general conditions of contracts in China.

To achieve these objectives, content analysis was used to assess overall document relevance with respect to a given information need (information retrieval, filtering, document categorization, and clustering). For sample purposes, all sub- clauses in AIA-A201 and GF-1999-0201 were examined. This study only examined AIA-A201 and GF-1999-0201 because these two standardized formats of general conditions are the most commonly used in building construction projects and on projects designed primarily by architects in the United States and China, respectively, despite the increasingly standardized formats published by different professional associations.

Prior coding was used in the study. Six categories were established prior to the analysis based on theories and the pilot study. Those are Rights and Obligations, Process, Quality, Cost, Administration, and Others. Treating an individual subclause as the unit of analysis, each subclause listed in a document was coded with respect to the six categories. Each category is defined as follows:

1. Rights and Obligations: Clauses that state the rights which exist under the rules of legal systems and obligations which incur a penalty for lack of fulfillment on the role and responsibility of all parties.

2. Process: Clauses that state the role and responsibility of all parties on the operations of construction in different phases and involved events related to planning, scheduling, managing, cleanup, claims, etc., during construction which could lead to any changes in production, time schedule, and completion of project.

3. Quality: Clauses that state the perception of the degree with the methods of testing, submittal, work procedure, the inspection standards, and warranty to which the construction project meets the owner's expectations, authority's requirements, and/or specific functional requirements.

4. Cost: Clauses that state any fee arrangement, fee payment method, change order, claims, bond, interest, insurance, lien, license fees, damages/losses, expenses/royalties, reimbursements, compensation, and guaranteed maximum price of the project between the parties whereby the total amount payable, payment, or additional/reduction cost to or from the involved parties for the construction which is restricted to a preagreement or acceptance of work.

5. Administration: Clauses that state any legalized management procedures, operations, and applications of organizing, coordinating, managing, and performing activities, information, problems, safety, resources, and labor in such a way that it delivers all the work required to complete the project within agreements, defined scope, time, and cost constraints.

6. Others: Clauses that do not meet any of the categories listed above.

\section{Comparison of AIA-A201 and GF-1999-0201}

For the purpose of this study, the SPSS computer software was used to analyze the data. In order to examine differences across six categories in AIA-A201 and GF-1999-0201, respectively, the one-sample chi-square $\left(\chi^{2}\right)$ tests were used to evaluate whether the proportions of subclauses which fell into categories were equal or not. The one-sample chi-square tests were also used to examine the proportion differences between AIA-A201 and GF1999-0201 within each of the six categories.

AIA-A201 Part 1 General-Conditions Document consists of 14 articles, with a total subclause of 254 , as summarized in Table 1. GF-1999-0201 General-Conditions Document consists of 11 articles, with a total subclause of 176, as shown in Table 2 .

As summarized in Table 3, AIA-A201, overall, had more subclauses than GF-1999-0201. AIA-A201 consists of 14 articles with a total of 254 subclauses while GF-1999-0201 had 11 ar- 
Table 1. AIA-A201 General Condition across Categories

\begin{tabular}{|c|c|c|c|c|c|c|c|}
\hline & Rights and Obligations & Process & Quality & Cost & Administration & Others & Total \\
\hline 1. General provisions & 7 & 0 & 0 & 0 & 0 & 8 & 15 \\
\hline 2. Owner & 8 & 0 & 0 & 0 & 1 & 0 & 9 \\
\hline 3. Contractor & 19 & 5 & 5 & 6 & 6 & 4 & 45 \\
\hline 4. Administration of the contract & 11 & 5 & 1 & 7 & 17 & 2 & 43 \\
\hline 5. Subcontractor & 8 & 0 & 0 & 0 & 1 & 0 & 9 \\
\hline 6. Construction by owner or by separate contractors & 4 & 0 & 0 & 3 & 3 & 0 & 10 \\
\hline 7. Changes in work & 1 & 4 & 0 & 5 & 5 & 0 & 15 \\
\hline 8. Time & 4 & 2 & 0 & 0 & 3 & 1 & 10 \\
\hline 9. Payments and completion & 5 & 0 & 5 & 20 & 0 & 0 & 30 \\
\hline 10. Protection of persons and property & 12 & 0 & 0 & 0 & 2 & 0 & 14 \\
\hline 11. Insurance and bonds & 11 & 0 & 0 & 7 & 1 & 0 & 19 \\
\hline 12. Uncovering and correction of work & 2 & 0 & 4 & 2 & 0 & 0 & 8 \\
\hline 13. Miscellaneous provision & 5 & 0 & 5 & 2 & 1 & 1 & 14 \\
\hline 14. Termination or suspension of the contract & 7 & 2 & 0 & 3 & 1 & 0 & 13 \\
\hline Total & 104 & 18 & 20 & 55 & 41 & 16 & 254 \\
\hline Percentage & 41 & 7 & 8 & 22 & 16 & 6 & 100 \\
\hline
\end{tabular}

ticles with a total of 176 subclauses. Furthermore, as shown in Table 3, the proportions of each category in GF-1999-0201 were smaller than those in AIA-A201 except for two categories: (1) Rights and Obligations and (2) Administration. In these two categories, the proportions of subclauses in GF-1999-0201 were greater than those in AIA-A201.

In both AIA-A201 and GF-1999-0201, more than $40 \%$ of the subclauses fell into the category of Rights and Obligations (AIA-A201 =49\%, GF-1999-0201=41\%). In addition, Rights and Obligations contributed the biggest proportion among all the six categories in both AIA-A201 and GF-1999-0201. Comparing AIA-A201 and GF-1999-0201 within the Rights and Obligations category, the proportion in GF-1999-0201 was bigger than the one in AIA-A201 by $8 \%$. Chi-square analysis revealed that this difference was statistically significant, $\chi^{2}=6.81, p<0.05$. In other words, GF-1999-0201 had significantly more subclauses that address the two parties' rights and obligations than AIA-A201 did.

The second major component of AIA-A201 was the costrelated subclauses, $22 \%$ of subclauses in AIA-A201. On the other hand, the second major element of GF-1999-0201, instead of being consistent with AIA-A201, was the administration-related subclauses $(p=0.22)$. Furthermore, the Cost category was ranked as the third major component in GF-1999-0201 while the Admin- istration category was the third one in AIA-A201. Together, in AIA-A201, the subclauses categorized as Cost were more than those categorized as Administration, whereas in GF-1999-0201, the ratio was completely opposite. Although the proportions of Cost and Administration were ranked differently in AIA-A201 and GF-1999-0201, attention should be given to the fact that the differences between those two categories in both AIA-A201 and GF-1999-0201 were not statistically significant.

Examining the Cost category across AIA-A201 and GF-19990201, the proportion in AIA-A201 was greater than the one in GF-1999-0201 by 7\%. Chi-square analysis revealed that this difference was not statistically significant, $\chi^{2}=0, p>0.05$. Nevertheless, comparing AIA-A201 and GF-1999-0201 within the Administration category, the proportion in AIA-A201 was less than the one in GF-1999-0201 by 6\%. Chi-square analysis revealed that this difference was statistically significant, $\chi^{2}=4.53$, $p<0.05$. In short, although AIA-A201 and GF-1999-0201 addressed cost-related subclauses similarly, GF-1999-0201 addressed significantly more administration-related subclauses than AIA-A201 did.

In both AIA-A201 and GF-1999-0201, subclauses categorized as Process, Quality, and Others composed small proportions of the general conditions. Within each of those categories, the pro-

Table 2. GF-1999-0201 General Condition across Categories

\begin{tabular}{|c|c|c|c|c|c|c|c|}
\hline & Rights and Obligations & Process & Quality & Cost & Administration & Others & Total \\
\hline 1. The definition of terms and contract documents & 13 & 1 & 0 & 3 & 9 & 5 & 31 \\
\hline 2. The general rights and obligations of both sides & 15 & 0 & 0 & 0 & 5 & 0 & 20 \\
\hline 3. The organizational design and construction period & 4 & 6 & 0 & 0 & 1 & 0 & 11 \\
\hline 4. Quality inspection & 6 & 0 & 4 & 0 & 6 & 0 & 16 \\
\hline 5. Construction safety & 4 & 0 & 0 & 0 & 2 & 0 & 6 \\
\hline 6. The payment of the contract price & 3 & 0 & 0 & 7 & 2 & 0 & 12 \\
\hline 7. Material supplies & 4 & 0 & 3 & 1 & 4 & 0 & 12 \\
\hline 8. Construction revision & 3 & 1 & 0 & 4 & 1 & 0 & 9 \\
\hline 9. Turnover and startup & 3 & 1 & 2 & 4 & 6 & 1 & 17 \\
\hline 10. Contract beach, claims, and disagreements & 5 & 0 & 0 & 3 & 0 & 0 & 8 \\
\hline 11. Others & 25 & 0 & 0 & 5 & 3 & 1 & 34 \\
\hline Total & 85 & 9 & 9 & 27 & 39 & 7 & 176 \\
\hline Percentage & 49 & 5 & 5 & 15 & 22 & 4 & 100 \\
\hline
\end{tabular}


Table 3. Summary of AIA-A201 and GF-1999-0201

\begin{tabular}{lrrrrrr}
\hline & \multicolumn{2}{c}{ AIA-A201 } & & \multicolumn{2}{c}{ GF-1999-0201 } \\
\cline { 2 - 3 } \cline { 5 - 6 } & Counts & Percentage & & Counts & Percentage \\
\hline 1. Rights and Obligations & 104 & 41 & & 85 & 49 \\
2. Process & 18 & 7 & & 9 & 5 \\
3. Quality & 20 & 8 & & 9 & 5 \\
4. Cost & 55 & 22 & & 27 & 15 \\
5. Administration & 41 & 16 & & 39 & 22 \\
6. Others & 16 & 6 & & 7 & 4 \\
Total & 254 & 100 & & 176 & 100 \\
\hline
\end{tabular}

portion in GF-1999-0201 was about 2\% less than the one in AIAA201. Chi-square analysis revealed that the proportion differences between AIA-A201 and GF-1999-0201 within the Process, Quality, and Others categories did not vary significantly. In other words, subclauses that regulate process-, quality-, and other-related issues were similarly addressed in both AIA-201 and GF-1999-0201.

Results of the detailed examination also indicated that between AIA-A201 and GF-1999-0201, only 11 out of all the subclauses across six categories could be paired with one another. Table 4 shows the subclauses from AIA-A201 that can be found a match in GF-1999-0201.

Although the remaining subclauses in AIA-A201 and GF1999-0201 could not exactly be matched from one to another, together they covered similar issues in different ways. However, some issues addressed in 21 of the GF-1999-0201 subclauses were missing in AIA-A201. Table 5 provides a list of the 21 GF-1999-0201 subclauses across six categories that addressed the issues that had been absent from AIA-A201.

Overall, the content of subclauses in AIA-A201 and GF-19990201 is similar yet different in several ways as listed below.

1. Subclauses in AIA-A201 were expressed in all areas in detail, commonly with lengthy statements interconnected in between; the subclauses of GF-1999-0201 were short, independent, and categorized in specific areas.

2. AIA-A201 covered the Owner, Architect, and Contractor involved under the agreement with further coverage for subcontractor; GF-1999-0201 covered the Owner, the Owner's authorized representative, and the Contractor.

3. There was no specific time limitation on administrative procedures related to the review and approve or reject process

Table 4. Paired Subclauses from AIA-A201 and GF-1999-0201

\begin{tabular}{ll}
\hline Category AIA-A201 &
\end{tabular}

Rights and Obligations

Quality

Cost

Administration

Others
2.1.1 The Owner is the person or entity identified as such in the Agreement and is referred to throughout the Contract Documents as if singular in number. The Owner shall designate in writing a representative who shall have express authority to bind the Owner with respect to all matters requiring the Owner's approval or authorization. Except as otherwise provided in Subparagraph 4.2.1, the Architect does not have such authority. The term "Owner" means the owner or the Owner's authorized representative.

3.1.1 The Contractor is the person or entity identified as such in the Agreement and is referred to throughout the Contract Documents as if singular in number. The Contractor shall be lawfully licensed, if required in the jurisdiction where the Project is located. The Contractor shall designate in writing a representative who shall have express authority to bind the Contractor with respect to all matters under this Contract. The term "Contractor" means the Contractor or the Contractor's authorized representative.

11.2 The Owner shall be responsible for purchasing and maintaining the Owner's usual liability insurance.

12.1.2 If a portion of the Work has been covered which the Architect has not specifically requested to examine prior to its being covered, the Architect may request to see such Work and it shall be uncovered by the Contractor. If such Work is in accordance with the Contract Documents, costs of uncovering and replacement shall, by appropriate Change Order, be at the Owner's expense. If such Work is not in accordance with the Contract Documents, such costs and the cost of correction shall be at the Contractor's expense unless the condition was caused by the Owner or a separate contractor in which event the Owner shall be responsible for payment of such costs.

12.2.1 The Contractor shall promptly correct Work rejected by the Architect or failing to conform to the requirements of the Contract Documents, whether discovered before or after Substantial Completion and whether or not fabricated, installed or completed. Costs of correcting such rejected Work, including additional testing and inspections, the cost of uncovering and replacement, and compensation for the Architect's services and expenses made necessary thereby, shall be at the Contractor's expense.

9.1 The Contract Sum is stated in the Agreement and, including authorized adjustments, is the total amount payable by the Owner to the Contractor for performance of the Work under the Contract Documents.

3.4.2 Except in the case of minor changes in the Work authorized by the Architect in accordance with Sections 3.12.8 or 7.4, the Contractor may make substitutions only with the consent of the Owner, after evaluation by the Architect and in accordance with a Change Order or Construction Change Directive.

3.11 The Contractor shall maintain at the site for the Owner one copy of the Drawings, Specifications, Addenda, Change Orders and other Modifications, in good order and marked currently to indicate field changes and selections made during construction, and one copy of approved Shop Drawings, Product Data, Samples and similar required submittals. These shall be available to the Architect and shall be delivered to the Architect for submittal to the Owner upon completion of the Work as a record of the Work as constructed.

8.1.2 The date of commencement of the Work is the date established in the Agreement.

1.1.4 The Project is the total construction of which the Work performed under the Contract Documents may be the whole or a part and which may include construction by the Owner or by separate contractors.

8.1.4 The term "day" as used in the Contract Documents shall mean calendar day unless otherwise specifically defined. 


Category Subclauses of GF-1999-0201 (translated by the writers)

Rights and Obligations

Process

Quality

Cost
4.2 The Contractor shall not transfer any drawings to a third party within the consent of the Owner. After the quality warranty period is ended, the Contractor shall return all drawings back to the Owner besides the required drawings by the Contractor for record.

15.2 If disagreement appears between the Owner and the Contractor on the quality of the Work, tests and inspections shall be performed by an independent consultant approved by both parties. The party who fails to prove its say shall be responsible for all the expenses and related losses. When both parties have the same responsibility, the expense and related losses shall be equally shared.

16.4 Because of a mistake or false instruction made by the Owner's authorized representative in result of additional construction costs, it is at the Owner's responsibility.

19.6 The Owner shall be responsible for tests and inspections on any portion of the Work related to manufacturing. If the Owner requests tests and inspections on the Work related to manufacturing before its completion acceptance or needed the coordination of the Contractor in construction operation, it requires the consent of the Contractor and additional agreement in contract between the Owner and the Contractor.

22.1 When major accidents related to human fatalities and any safety related incidents happened, the Contractor shall notify the legal authority and the Owner's authorized representative immediately and shall promptly file report to the associated governmental agency for proper investigation. The party which is responsible for the accident or incident shall pay for all expenses and losses.

28.6 The Owner does not have rights to choose manufacturer or distributor for materials and equipment furnished by the Contractor.

39.1 Unavoidable events: It includes wars, raids, air crashes to site, or other incidents that is not caused by the Owner or the Contractor and results in explosion or fire; it also includes natural disasters like storm, rain, snow, flood, and earthquake.

39.4 If one party fails to perform the duties and obligations in accordance with the contract before an unavoidable event happens, the event does not waive the responsibility of the party.

43.1 The Contractor shall promptly secure the site and shall report to the Owner's authorized representative within $4 \mathrm{~h}$ when ancient tombs, historical buildings or sites, fossils, or valuable items beneficial to the study of archeology and geology are discovered at the site. The Owner's authorized representative shall report to the authority in charge of historical management within $24 \mathrm{~h}$ of the discovery. The Owner and the Contractor shall follow the instruction from the authority on how to handle and protect the discovery. The Owner shall be responsible for additional expense on the project and the construction schedule shall be extended accordingly. If the discovery is being hidden by any party from the authority and it results in damages on it, the party who is responsible will be prosecuted by laws.

13.1 With the delay approval from the Owner's authorized representative to the Contractor, the construction schedule can be extended due to the following causes: (1) the Owner has not provided the drawings under the contract and has not reached a final agreement on the project with the Contractor; (2) the Owner has not made the payments to the Contractor to financially support the project before or during the construction; (3) the Owner's authorized representative does not provide necessary instructions and approvals in accordance with the contract which result in the construction operation; (4) due to the revision on design during construction and workload increases; (5) due to the supply or noncontractor-related causes on shortage of water, electricity, or gas for more than a total of $8 \mathrm{~h}$ within 1 week; (6) due to unavoidable events; and (7) in accordance with the contract agreement or the Owner's authorized representative approval on other events.

27.5 The Contractor shall test and inspect the material furnished by the Owner before using it. If the material fails the tests and inspections, it shall not be used for the Work. All costs of tests and inspections shall be at the Owner's expense.

34.1 The Contractor shall warrant to the Owner on the Work in accordance with the current laws, government standards, and related country's warranty policies.

23.3 The tolerable reasons for adjusting the contract sum: (1) due to changes on current laws, government standards, and related country's policies; (2) due to changes on pricing by the Ministry of Construction (2002a,b), (3) due to the supply or noncontractor-related causes on shortage of water, electricity, or gas for more than a total of $8 \mathrm{~h}$ within a week; and (4) the agreement between the Owner and the Contractor. between the Owner's representative and the Contractor in AIA-A201, while a specific time limit was clearly indicated in GF-1999-0201 on the response from the Owner's authorized representative to the Contractor and vice versa.

4. AIA-A201 clearly addressed issues related to the construction project such as the handling of waste materials, job site maintenance, and cleaning up after each phase of construction. On the other hand, GF-1999-0201 mentioned nothing about these specific areas.

5. No subclauses were stated to protect historic sites or proper response to the authority in AIA-A201; GF-1999-0201 pro- vided specific procedures for the proper response to the discovery of historical sites/objects at the construction site and to notify the authorities in a timely manner.

6. AIA-A201 provided the information on the responsibilities and involvement of the subcontractor in detail under the general conditions; GF-1999-0201 had no information provided regarding the subcontractor besides addressing the rights of the Contractor to subcontract a portion of the work (not all the work) to separate contractors with the consent of the Owner or the Owner's authorized representative.

7. AIA-A201 had specific restrictions and procedures on the 
construction administration related to managing construction documents or exchanging information between parties; GF1999-0201 had minimum requirements on construction administration, with the main focus being the requirements of the Contractor to obtain approval or response from the Owner's authorized representative on procedures and time limitations applicable to submitting of or responding to any documents and vice versa.

8. AIA-A201 described the required 1-year warranty from the Contractor on the project after completion; GF-1999-0201 has no specific time requirements on the quality warranty by the Contractor after project completion except as specified by the agreement reached between the Owner and the Contractor in the contract or in local bylaws.

9. GF-1999-0201 clearly stated that any job delays due to wars, raids, or accidents caused by a third party that resulted in explosion or fire should not be at the Contractor's expenses; AIA-A201 had a broad, unspecific coverage on this issue.

10. AIA-A201 clearly addressed the responsibility of expenses related to taxes, permits, fees, etc. On the other hand, GF1999-0201 mentioned nothing about who shall be responsible for these expenses.

\section{Conclusions and Recommendations}

This study was an investigation of the differences in standardized general conditions between AIA-A201 and GF-1999-0201 that are used in the United States and China, respectively. This session offers a discussion on the major findings of the study and their applications to practice. In addition, recommendations for future research are proposed.

The content analysis revealed that the subclauses being categorized into each of six categories were in similar proportions between both AIA-A201 and GF-1999-0201. In addition, the allocation of each category was correspondingly delineated. This finding suggests that in both standardized general conditions have the same value in terms of what are the important and critical issues that should be addressed and regulated in a generalconditions document.

The findings of this study confirm that the rights and obligations issues of each party involved under the agreement were the major component of the standardized general conditions in both AIA-A201 and GF-1999-0201. This finding is consistent with the statement of Sweet (1999) that general conditions provide clear and complete ground rules of the duties and rights of the parties. Furthermore, one can conclude that both AIA-A201 and GF1999-0201 are used as contract documents to establish project relationships, specify each party's rights and obligations, define terms, and assign responsibilities.

The findings of the detailed examination reveal that the content of subclauses in AIA-A201 and GF-1999-0201 is different in several ways. These differences may have been caused by cultural, historical, geographical, political, and language variations in the American and Chinese construction markets. In other words, although the subclauses in AIA-A201 and GF-1999-0201 function similarly in terms of establishing project relationships among parties, they are different by the nature of the market that they take on.

Based on the differences between AIA-A201 and GF-19990201 discussed above, the following recommendations were made for American companies (owners, architectural and engineering firms, and construction companies). First of all, American companies which use AIA-A201 as their general conditions of construction contract in China should add subclauses that are important in the Chinese market but absent in AIA-A201, such as subclauses that address each party's rights and obligations in handling ancient tombs, historical buildings or sites, fossils, or valuable items beneficial to the study of archeology and geology that are discovered at the site, subclauses which regulate that the Contractor shall warrant to the Owner on the Work in accordance with the current laws, government standards, and related country's warranty policies, and so on. By adding and adapting subclauses from GF-1999-0201, American companies will be able to possess and develop a more comprehensive format of standardized general conditions that can be used in the Chinese market without complications.

Next, when conducting business in China, American companies should be aware of the expectation of roles that each party takes may be different from that in the United States. For example, in China architects and engineers are required and expected to act as owner's authorized representatives. In addition, American companies should also be aware that those who are using GF-1999-0201 may have different presumption toward AIA-A201. Therefore, good communication with the cooperating Chinese construction companies or design firms is critical. It is also important for the U.S. design and engineering firms or construction companies to understand the differences in their contract and make sure each party involved read through the overall general conditions before signing the contract that uses GF-19990201.

Based on the results, two recommendations for future research are offered. This study merely investigated differences between two standardized formats of general conditions used in the United States and China. Therefore, comparisons among different types of standardized general conditions, such as those developed by the AGC and the ASCE, the U.S. government (federal acquisition regulations), the Engineers Joint Contract Documents Committee, and the International Federation of Consulting Engineers (FIDIC), are suggested for future studies. Moreover, a further investigation of the discrepancy between building construction and engineering construction is also recommended.

This study simply examined the content differences of AIAA201 and GF-1999-0201 without taking considerations of finding and understanding the general challenges that already exist in practice. Qualitative studies that investigate the nature of problems and the assurance of compliance in the context of an actual or hypothetical construction project situation that American companies have encountered in applying AIA-A201 or other generalconditions documents in China are strongly recommended for future research. In addition to portraying challenges, the perceived causes of those challenges and American manufacturers' (owners), architectural and engineering firms', and construction companies' experiences in coping with their difficulties in the current Chinese market are valuable information for future development of standardized general conditions for construction contract in the Chinese market.

\section{References}

Bockrath, J. T. (2000). Contracts and the legal environment for engineers and architects, 6th Ed., McGraw-Hill, New York.

Bubshait, A. A., and Almohawis, S. A. (1994). "Evaluation the general conditions of a construction contract." Int. J. Proj. Manage., 12(3), $133-136$. 
Clough, R. H., Sears, G. A., and Sears, S. K. (2005). Construction contracting: A practical guide to company management, 7th Ed., Wiley, Hoboken, N.J.

Fisk, E. R. (2002). Construction project administration, 7th Ed., Wiley, Hoboken, N.J.

Hinze, J. (2001). Construction contracts, 2nd Ed., McGraw-Hill, New York.

Ministry of Construction. (2002a). "The regulation of foreign invested construction enterprises." 113th Joint Ordinance, Ministry of Construction and Ministry of Foreign Trade and Economic Cooperation (MOFTEC), Beijing.
Ministry of Construction. (2002b). "The regulation of foreign invested construction engineering design enterprise." Joint Ordinance, Ministry of Construction and Ministry of Foreign Trade and Economic cooperation (MOFTEC), Beijing.

National Bureau of Statistics of China. (2009). China statistical abstract 2009, China Statistics Press, Beijing.

Sweet, J. (1999). Legal aspects of architecture, engineering, and the construction process, 6th Ed., Brooks/Cole Publishing Company, Pacific Grove, Calif.

The Associated General Contract of America. (2010). 〈http://www.agc. org $($ Feb. 17, 2010). 